\title{
Evaluation of Leptin Receptor Q223R (rs1137101) Polymorphism Based on Histopathological and Body Mass Index Characteristics in Iranian Females with Breast Cancer
}

\author{
Zahra Tahmasebi Fard (ib) ${ }^{1, *}$ \\ ${ }^{1}$ Department of Biology, Roudehen Branch, Islamic Azad University, Roudehen, Iran \\ "Corresponding author: Associated Professor of Cellular and Molecular Biology, Department of Biology, Roudehen Branch, Islamic Azad University, Roudehen, Iran. Email: \\ ztahmasebi@riau.ac.ir, ztahmasebifard@yahoo.com
}

Received 2019 April 30; Revised 2020 February 15; Accepted 2020 March 26.

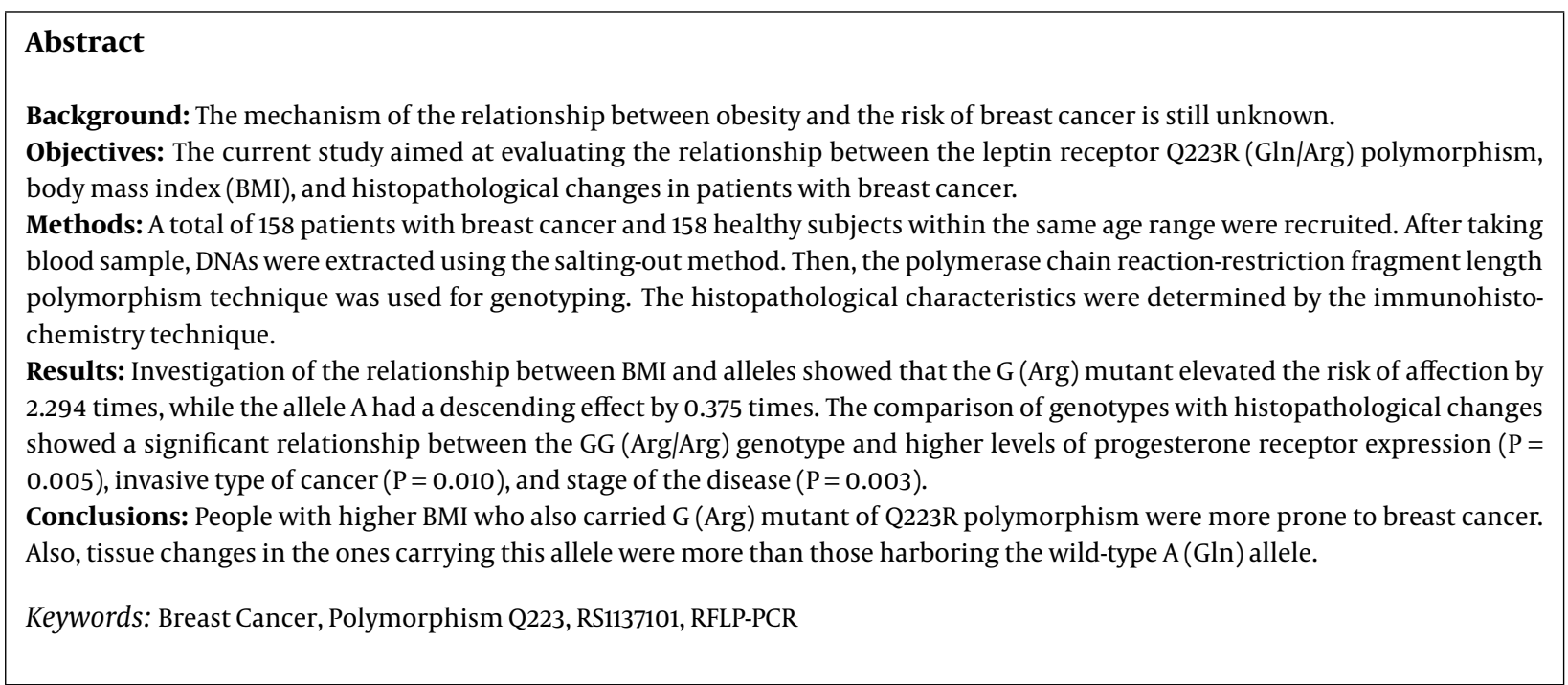

\section{Background}

Obesity occurs due to the combined effects of genes, environment, and lifestyle, as well as the interaction of these factors (1). Postmenopausal obesity increases the risk of breast cancer in females by $30 \%-50 \%$. In addition, higher BMI is significantly associated with increased risk of inflammatory breast cancer in both menopausal and postmenopausal females. It is reported that patients with obesity exhibit larger and more advanced tumors and more invasive pathological features of cancer, such as lymph node metastases (2).

Adipose tissue and its associated semi-cytokine proteins- i.e., adipokines, especially leptin and adiponectin- were investigated as the obesity-associated mediators of breast cancer. Higher levels of leptin in individuals with obesity can act as a growth-promoting factor, while the lower levels of adiponectin in females with obesity might be useful in the growth-promoting effects of leptin since adiponectin has anti-proliferative effects (3).

Leptin is a protein hormone that is mainly produced by adipocytes, placenta, and breast epithelium, and plays an important role in controlling the metabolism, reproductive processes, immune responses, angiogenesis, hematopoiesis, and oxidation of lipids. Leptin can promote the development of breast tumors through several mechanisms such as modulation of the extracellular environment, reduction of apoptosis, or enhancing the regulation of anti-apoptotic genes (4).

Leptin is a $16-\mathrm{kDa}$ cytokine encoded by the $o b$ gene. It was first identified in 1994 as a regulator of body weight and energy balance through the hypothalamus. Leptin exerts its effect through the transmembrane leptin receptor, ObR. In human tissue, at least four different isoforms of ObR with different $\mathrm{COOH}$ domains are identified; the ObR1 lengths 1165 amino acids and consists of extracellular, transmembrane, and intracellular domains. Short iso- 
forms lack the downstream domains to transmit the signal (5).

One of the leptin receptor gene polymorphisms (LEPRs) is A to G substitution in exon 6 at nucleotide 668 and codon 223 of the initiation codon, LEPR Q223R (rs1137101), which in turn disrupts the leptin binding activity. LEPR Q223R polymorphism is associated with a decrease in BMI, fat mass, serum leptin levels, and systolic and diastolic blood pressures. Other studies, however, contradict these findings (6); for example, Liu and Liu, in a meta-analysis study, showed that LEPR Q223R polymorphism can contribute to the spread of breast cancer in East Asia (7). Another meta-analysis by Wang et al., on 10 studies including 2759 patients and 4464 controls, showed that rs1137101 and rs1137100 polymorphisms are significantly associated with the risk of breast cancer (8).

\section{Objectives}

In the current study, the presence of rs1137101 polymorphism was evaluated in some patients with breast cancer compared with the control group, in terms of BMI and histopathological changes.

\section{Methods}

\subsection{Sample Study}

A total of 158 females with breast cancer and 158 healthy controls referring to Shohada-e-Tajrish Hospital, Tehran, Iran were recruited. Blood samples were taken from all the subjects after physical and clinical examinations and diagnosis confirmation by the specialist.

\subsection{Inclusion and Exclusion Criteria}

Patients who needed surgery were selected and confirmed by biochemical tests and mammography of their cancer. Those who had previously received radiotherapy or chemotherapy were excluded. Control subjects had no history of high blood pressure, diabetes, and cardiovascular diseases; in addition, none of them had cancer, including breast cancer.

\subsection{RCR-RFLP Technique}

A 3 - $5 \mathrm{~mL}$ blood sample was taken from each subject after obtaining the informed consent; then, the blood sample was added to $0.5 \mathrm{mM}$ EDTA to be prepared for DNA extraction by salting out method. Specific primers were used to amplify the Q223R polymorphism fragment. The sequence and length of the amplified fragment are shown in Table 1.
For each PCR reaction, $10 \mu \mathrm{L}$ water, $10 \mu \mathrm{L}$ Amplicon $2 \mathrm{X}$ Mastermix (containing $1.5 \mathrm{mg} \mathrm{MgCl}_{2}$, buffer, DNA Taq polymerase, and dNTP plus other materials required for the reaction), $1 \mu \mathrm{L}$ of each $10-\rho$ mol primers, and $100 \mathrm{ng}(1 \mu \mathrm{L})$ the genomic DNA of each patient were mixed. The PCR mixture was then vortexed and the microtubes were placed in a thermocycler (Eppendorf Mastercycler gradient, Germany) apparatus for the amplification a 366-bp fragment of LepR gene according to the following program: $95^{\circ} \mathrm{C}$ for 5 minutes in one cycle, $95^{\circ} \mathrm{C}$ for 60 seconds, $60^{\circ} \mathrm{C}$ for $30 \mathrm{sec}$ onds, $75^{\circ} \mathrm{C}$ for 40 seconds in 35 cycles, and $72^{\circ} \mathrm{C}$ for $5 \mathrm{~min}$ utes in one cycle. The final PCR products as well as a 100-bp (Roche) marker, were electrophoresed on a 1.5\% SYBR ${ }^{\circledR}$ Safe DNA Gel Stain at a constant voltage of $95 \mathrm{~V}$ for 15 to $20 \mathrm{~min}$ utes to visualize the bands. The results of the amplification of some samples are shown in Figure 1.

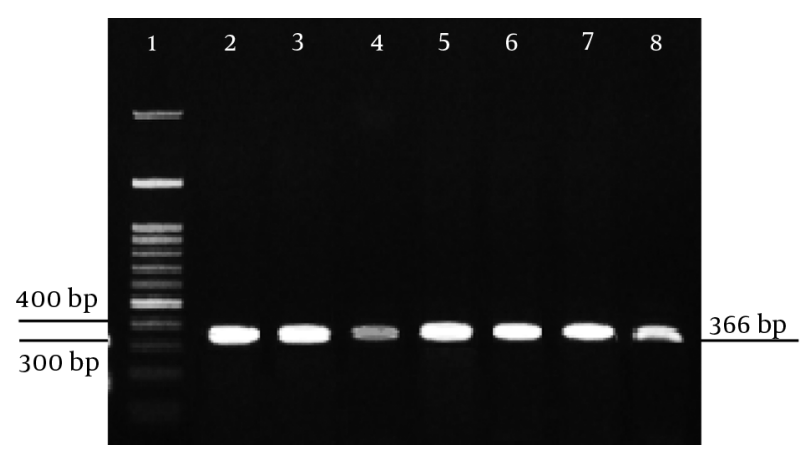

Figure 1. The results obtained from the electrophoresis of PCR products of rs113710 polymorphism on $1.5 \%$ agarose gel. First well is Marker (100 bp), Wells 2- 4 normal samples, and wells 5-8 is cancerous samples.

After visualization of the 366-bp band, a portion of the amplified sample was added to $5 \mathrm{U}$ of Msp I restriction enzyme, the enzyme buffer, and distilled water in a new $\mathrm{mi}-$ crotube and then incubated at $37^{\circ} \mathrm{C}$ for $16-18$ hours. The product of enzymatic digestion was run on $3 \%$ agarose gel. There was only one cutting site on the amplified segment of the enzyme, and based on the size of the fragments formed on the gel, the patients' genotypes were determined. The results of digestion for some samples are shown in Figure 2.

\subsection{Immunohistochemistry}

Appropriate paraffin blocks and slides were selected from each patient's samples for immunohistochemical testing. The tumor type and its degree were determined based on the Bloom Richardson system (9). Subsequently, the experimental stages were evaluated using specific antibodies (Dako, Denmark), estrogen, and progesterone. Slides were studied with light microscopy and the color 


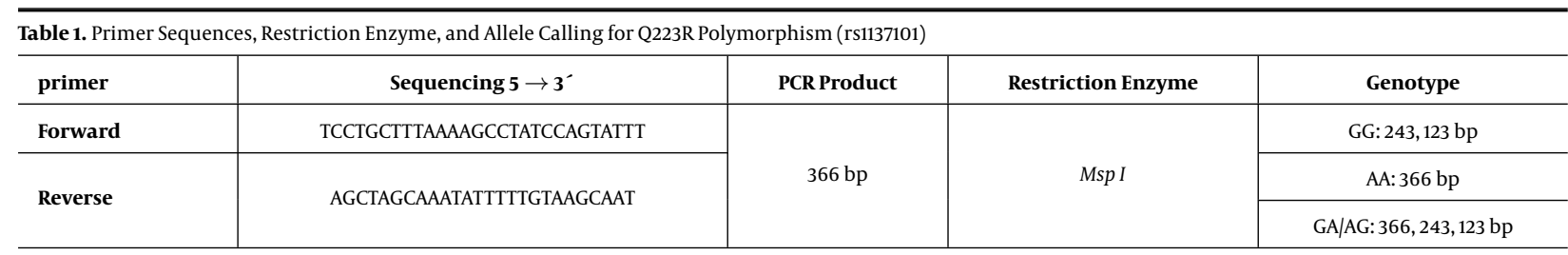

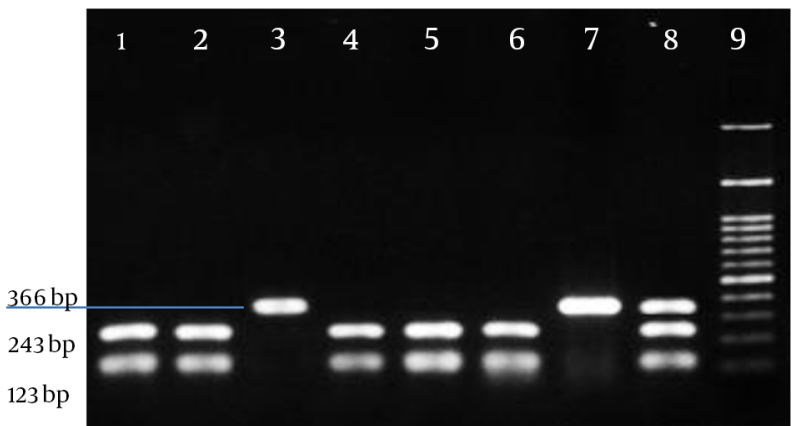

Figure 2. Results of digestion of PCR products (rs rs1137101) in cancerous samples; wells 1, 2, 4, 5, \& 6: genotype GG; wells 3 \& 7: genotype AA; wells 8: genotype AG/GA; wells 9: markers of DNA (100 bp).

intensity of at least $20 \%$ of tumor cells was considered as the positive boundary of estrogen and progesterone receptors.

\subsection{Statically Analysis}

Genotypes count, percentage, and frequency were determined in two groups of the cancer patients and the controls. The allele frequencies in both groups were determined using the Hardy-Weinberg equilibrium; then, the relationship between genotypes and the risk of breast cancer in two groups was evaluated by chi-squared test in SPSS version 23. The relationship between genotypes and breast cancer was evaluated by logistic regression based on the odds ratio (OR) and 95\% confidence intervals (CI). Pearson correlation coefficient was used to calculate the correlation between variables. $\mathrm{P}<0.05$ was considered as the level of significance.

\section{Results}

The mean age of patients with breast cancer and healthy controls were $58.54 \pm 0.64$ and $55.39 \pm 0.73$ years, respectively. The age and BMI data of the study subjects are shown in Table 2.

The direct counting method has been used for finding the frequency of the alleles and genotypes in the two groups. The frequency of the alleles was then calculated in both groups using the Hardy-Weinberg equilibrium model. The results of genotyping count showed that GG (Arg/Arg) genotype was 127 (80.38\%) in tumor samples and 108 (68.35\%) in control samples and a statistically significant difference was observed between the groups in terms of the genotype ( $\mathrm{P}=0.014$, OR: $1.897,95 \% \mathrm{CI}: 1.132$ 3.178). Genotype AA (Gln/Gln) was observed in 21 (13.29\%) tumor subjects and $42(26.58 \%)$ controls; there was a significant difference between the two groups in this regard ( $\mathrm{P}=0.003$, OR: 0.423, 95\%CI: 0.237 - 0.756). The heterozygote genotypes, the AG/GA (Gln/Arg), was observed in 10 (6.33\%) tumor patients and 8 (5.06\%) controls, but there was no relationship between the groups in terms of this genotype (P = 0.627, OR: 1.267, 95\%CI: 0.487 - 3.299). According to the Hardy-Weinberg principle, the frequency of the $\mathrm{G}$ allele was 0.835 in the cancer group and 0.709 in the control group. The frequency of the A allele was 0.165 in the cancer group and 0.291 in the control group. The results of the allele frequency and the relationship between the two groups are shown in Table 3.

The relationship between genotypes and estrogen and progesterone receptors expression, type of cancer, and the stage of the disease was also studied. Those who carried the mutant genotype showed more histopathological changes. The results are presented in Table 4.

The relationship between BMI and genotypes showed that the GG (Arg/Arg) genotype increased the risk of cancer by 2.294 times ( $\mathrm{P}=0.003, \mathrm{OR}: 2.579,95 \% \mathrm{CI}: 1.539$ - 4.323), but the genotype AA (Gln/Gln) reduced the risk of disease by 0.375 times ( $\mathrm{P}=0.0002$, OR: $0.436,95 \% \mathrm{CI}: 0.249-0.764)$. The results are shown in Table 5 .

The Pearson correlation coefficient was used to assess correlations between the variables. The BMI showed a positive correlation with the expression of estrogen receptor $(\mathrm{P}=0.001)$ and progesterone receptor $(\mathrm{P}=0.012)$, but a negative correlation with the type of cancer $(\mathrm{P}=0.0003)$ and stage of the disease $(\mathrm{P}=0.002)$.

\section{Discussion}

Obesity is associated with serious illnesses such as cancer. Obesity caused by the lifestyle and unhealthy diet also 


\begin{tabular}{|c|c|c|c|}
\hline \multirow{2}{*}{ Variable, Range } & \multicolumn{2}{|c|}{ Mean \pm SD Error Difference } & \multirow{2}{*}{ PValue } \\
\hline & Case & Control & \\
\hline Age, $y$ & & & 0.566 \\
\hline $40-50$ & $49(31.01)$ & $48(30.38)$ & \\
\hline $50-60$ & $68(43.04)$ & $56(35.44)$ & \\
\hline $60-70$ & $34(21.52)$ & $40(25.32)$ & \\
\hline $70 \leq$ & $7(4.43)$ & $14(8.86)$ & \\
\hline Mean \pm SD error difference & $58.54 \pm 0.64$ & $55.39 \pm 0.73$ & \\
\hline BMI, $\mathrm{kg} / \mathrm{m}^{2}$ & & & $8.2 \times 10^{-7}$ \\
\hline $25 \geq$ & $57(36.08)$ & $101(63.92)$ & \\
\hline $25<$ & $130(82.28)$ & $28(17.72)$ & \\
\hline Mean \pm std. error difference & $25.05 \pm 0.17$ & $23.91 \pm 0.15$ & \\
\hline
\end{tabular}

Abbreviations: BMI, body mass index; SD, standard deviation.

${ }^{\mathrm{a}}$ Continuous variable are reported as means $\pm \mathrm{SD}$, and discrete variables are expressed as No. (\%).

\begin{tabular}{lccccc}
\hline Table 3. Frequency of Alleles and Genotypes (rs1137101) Distributions of Characteristics Among Patients and Control Groups \\
\hline Allele/Genotype & Case & Control & Total & OR & CI95\% \\
\hline A & 52 & 92 & 144 & 0.480 & $0.325-0.709$ \\
G & 264 & 224 & 488 & 3.704 & $2.197-6.245$ \\
AA & 21 & 42 & 63 & $1.9 \times 10^{-4}$ & $2.6 \times 10^{-7}$ \\
GG + AG & 137 & 116 & 253 & 2.362 & $1.323-4.216$ \\
\hline
\end{tabular}

Abbreviations: CI, confidence interval; OR, odds ratio.

increases the risk of cancer. Many studies showed a significant relationship between obesity and high rate of death from cancer. However, the mechanism by which obesity can cause breast cancer is still unclear (10).

Studies in animals and humans also showed that leptin plays a pivotal role in the regulation of energy homeostasis, neuroendocrine function, metabolism, immune function, and bone metabolism (11). The mutations in the leptin and leptin receptor can reduce leptin receptor signaling. According to the results of different studies, mutations are associated with cancer in humans. It is recently reported that leptin and its receptor can lead to the initiation and progression of breast cancer. Regarding Q223R polymorphism, the glutamine (Gln) for arginine (Arg) substitution occurs at amino acid 223 in the second extracellular receptor of leptin (12). This change turns the neutral amino acid into the positive-charge one and affects the capacity of signaling and receptor function to such an extent that in homozygous $G$ allele carriers, higher levels of leptin are observed in hemoglobin that is associated with increased risk of breast cancer in female carriers (13). In addition, observations showed that functional variation in the leptin receptor gene is one of the important factors for the modifi- cation of obesity and BMI (14).

Previous reports indicated a significant relationship between $\mathrm{Q} / \mathrm{R}$ genetic variation in leptin receptor and breast cancer and reported a higher frequency of LEPR 223Arg allele in the patients group than the controls. According to studies carried out by Snoussi et al. (15), Han et al. (16), Gallicchio et al. (17), and Okobia et al. (18), this polymorphism was in correlation with the risk of breast cancer, which is in line with the results of the current study. In the present study, the frequencies of $G$ mutant allele in the patients and control groups were 0.84 and 0.71 , respectively; while the frequencies of wild-type A allele were 0.16 and 0.29 in the patients and the control groups, respectively. Also, the risk of the disease was 3.704 times higher in patients with $G$ allele than the ones with A allele, which indicates a strong association between this polymorphism and breast cancer.

The results of two recent studies by Mahmoudi et al. (12) and Mohammadzadeh et al. (13) on breast cancer samples of Iranian females are similar to those of the current study and seemingly can confirm the correlation of this polymorphism with breast cancer in Iranian females.

But contrary to the findings of the current study, those conducted by Woo et al. (19), Nyante et al. (20), El-Hussiny 


\begin{tabular}{|c|c|c|c|c|c|c|c|}
\hline & & Gln/Gln & P Value & Arg/Arg & P Value & Gln/Arg & PValue \\
\hline ER status & & & 0.731 & & 0.956 & & 0.569 \\
\hline Positive & & 17 & & 106 & & 9 & \\
\hline Negative & & 4 & & 21 & & 1 & \\
\hline PR status & & & 0.004 & & 0.005 & & 0.591 \\
\hline Positive & & 19 & & 72 & & 7 & \\
\hline Negative & & 2 & & 55 & & 3 & \\
\hline Type of cancer & & & 0.002 & & 0.010 & & 0.932 \\
\hline ILC & & 5 & & 46 & & 4 & \\
\hline IDC & & 9 & & 51 & & 3 & \\
\hline DCIS & & 1 & & 24 & & 2 & \\
\hline LCIS & & 6 & & 6 & & 1 & \\
\hline Stage of disease & & & 0.095 & & 0.003 & & 0.146 \\
\hline I & & 4 & & 24 & & 2 & \\
\hline II & & 1 & & 24 & & 0 & \\
\hline II/III & & 3 & & 32 & & 1 & \\
\hline III & & 6 & & 34 & & 3 & \\
\hline IV & & 7 & & 34 & & 4 & \\
\hline \multicolumn{8}{|c|}{$\begin{array}{l}\text { Abbreviations: DCIS, ductal carcinoma in situ; ER, estrogen receptor; IDC, invasive ductal carcinoma; ILC, invasive lobular carcinoma; LCIS, lobular carcinoma in situ; PR, } \\
\text { progesterone receptor. }\end{array}$} \\
\hline \multirow{3}{*}{ Genotype } & \multicolumn{4}{|c|}{ BMI } & \multirow{3}{*}{ PValue } & \multirow{3}{*}{ OR } & \multirow{3}{*}{ 95\%CI } \\
\hline & & & & & & & \\
\hline & Case & Control & Case & Control & & & \\
\hline Gln/Gln & 27 & 36 & 160 & 93 & 0.0002 & 0.375 & $0.249-0.764$ \\
\hline Arg/Arg & 153 & 82 & 34 & 47 & 0.003 & 2.294 & $1.539-4.323$ \\
\hline Gln/Arg & 7 & 11 & 180 & 118 & 0.071 & 0.417 & $0.157-1.107$ \\
\hline
\end{tabular}

Abbreviations: BMI, body mass index; $\mathrm{CI}$, confidence interval; OR, odds ratio.

et al. (21), as well as a meta-analysis by He et al. (22) showed no significant correlation between this polymorphism and breast cancer. It seems that reasons such as sample size, employed techniques, smoking and alcohol consumption, environmental factors affecting the lifestyle, and genetic changes in different populations and races can affect the contradictory results.

\subsection{Conclusions}

According to the obtained results, the leptin gene GG (Arg/Arg) genotype of Q223R polymorphism can be considered as a risk factor for the development of breast cancer. The carriers of this genotype who have obesity are at higher risk for breast cancer. Histopathological changes also confirmed the effect of this polymorphism on breast cancer.
It seems that genetic changes can alter the metabolism of breast tissue, increase their growth by hormones such as leptin, and elevate the risk of breast cancer. Further studies can confirm the results.

\section{Acknowledgments}

This work was supported by a grant from the Research Council of Roudehen University. The author would like to express their gratitude to the medical personnel at Shohaday-e-Tajrish Hospital in Tehran and all the patients who participated in this study. Special thanks to Dr. Nafisi for introducing the patients for the research. 


\section{Footnotes}

Conflict of Interests: The author has no conflicts of interest to declare.

Ethical Approval: Written informed consent was obtained from the subjects willing to participate. The Ethics Committee of the Islamic Azad University of Medical Branch reviewed and approved the study protocol (IR.IAU.TMU.REC.1395.292).

Funding/Support: All financial and materials for the research and work were supported by the Research Department of the Islamic Azad University of Roudehen Branch. This article is taken from the approved research plan (project code: 93.40086).

Patient Consent: Written informed consent was obtained from the subjects willing to participate.

\section{References}

1. Yiannakouris N, Yannakoulia M, Melistas L, Chan JL, Klimis-Zacas $\mathrm{D}$, Mantzoros CS. The Q223R polymorphism of the leptin receptor gene is significantly associated with obesity and predicts a small percentage of body weight and body composition variability. $J$ Clin Endocrinol Metab. 2001;86(9):4434-9. doi: 10.1210/jcem.86.9.7842. [PubMed: 11549688].

2. Surmacz E. Obesity hormone leptin: A new target in breast cancer? Breast Cancer Res. 2007;9(1):301. doi: 10.1186/bcr1638. [PubMed: 17274833]. [PubMed Central: PMC1851379].

3. Grossmann ME, Ray A, Nkhata KJ, Malakhov DA, Rogozina OP, Dogan $S$, et al. Obesity and breast cancer: Status of leptin and adiponectin in pathological processes. Cancer Metastasis Rev. 2010;29(4):641-53. doi: 10.1007/s10555-010-9252-1. [PubMed: 20821253].

4. Niu J, Jiang L, Guo W, Shao L, Liu Y, Wang L. The association between leptin level and breast cancer: A meta-analysis. PLoS One. 2013;8(6). e67349. doi: 10.1371/journal.pone.0067349. [PubMed: 23826274]. [PubMed Central: PMC3694967].

5. Garofalo C, Surmacz E. Leptin and cancer.J Cell Physiol. 2006;207(1):1222. doi: 10.1002/jcp.20472. [PubMed: 16110483].

6. Boumaiza I, Omezzine A, Rejeb J, Rebhi L, Ouedrani A, Ben Rejeb $\mathrm{N}$, et al. Relationship between leptin G2548A and leptin receptor Q223R gene polymorphisms and obesity and metabolic syndrome risk in Tunisian volunteers. Genet Test Mol Biomarkers. 2012;16(7):72633. doi: 10.1089/gtmb.2011.0324. [PubMed: 22734460]. [PubMed Central: PMC3396002].

7. Liu C, Liu L. Polymorphisms in three obesity-related genes (LEP, LEPR, and PON1) and breast cancer risk: A meta-analysis. Tumour Biol. 2011;32(6):1233-40. doi: 10.1007/s13277-011-0227-9. [PubMed: 21887553].

8. Wang LQ, Shen W, Xu L, Chen MB, Gong T, Lu PH, et al. The association between polymorphisms in the leptin receptor gene and risk of breast cancer: A systematic review and pooled analysis. Breast Cancer Res Treat. 2012;136(1):231-9. doi: 10.1007/s10549-012-2228-9. [PubMed: 22983835].

9. Rosai J. Ackerman's surgical pathology. 8th ed. St. Louis: Mosby Com; 1996. $1590 \mathrm{p}$.
10. La Vecchia C, Giordano SH, Hortobagyi GN, Chabner B. Overweight obesity, diabetes, and risk of breast cancer: Interlocking pieces of the puzzle. Oncologist. 2011;16(6):726-9. doi: 10.1634/theoncologist.20110050. [PubMed: 21632448]. [PubMed Central: PMC3228228]

11. Mantzoros CS, Magkos F, Brinkoetter M, Sienkiewicz E, Dardeno TA, Kim SY, et al. Leptin in human physiology and pathophysiology. Am J Physiol Endocrinol Metab. 2011;301(4):E567-84. doi: 10.1152/ajpendo.00315.2011. [PubMed: 21791620]. [PubMed Central: PMC3191548]

12. Mahmoudi R, Noori Alavicheh B, Nazer Mozaffari MA, Fararouei M, Nikseresht M. Polymorphisms of leptin (-2548 G/A) and leptin receptor (Q223R) genes in Iranian women with breast cancer. Int J Genomics. 2015;2015:132720. doi: 10.1155/2015/132720. [PubMed 26199932]. [PubMed Central: PMC4496654].

13. Mohammadzadeh G, Ghaffari MA, Bafandeh A, Hosseini SM. Effect of leptin receptor Q223R polymorphism on breast cancer risk. Iran J Basic Med Sci. 2014;17(8):588-94. [PubMed: 25422752]. [PubMed Central: PMC4240793].

14. Quinton ND, Lee AJ, Ross RJ, Eastell R, Blakemore AI. A single nucleotide polymorphism (SNP) in the leptin receptor is associated with BMI, fat mass and leptin levels in postmenopausal Caucasian women. Hum Genet. 2001;108(3):233-6. doi:10.1007/s004390100468. [PubMed: 11354636].

15. Snoussi K, Strosberg AD, Bouaouina N, Ben Ahmed S, Helal AN Chouchane L. Leptin and leptin receptor polymorphisms are associated with increased risk and poor prognosis of breast carcinoma. BMC Cancer. 2006;6:38. doi: 10.1186/1471-2407-6-38. [PubMed: 16504019]. [PubMed Central: PMC1397853].

16. Han CZ, Du LL, Jing IX, Zhao XW, Tian FG, Shi J, et al. Associations among lipids, leptin, and leptin receptor gene Gin223Arg polymorphisms and breast cancer in China. Biol Trace Elem Res. 2008;126(13):38-48. doi: 10.1007/s12011-008-8182-z. [PubMed: 18668212].

17. Gallicchio L, McSorley MA, Newschaffer CJ, Huang HY, Thuita LW, Hoffman SC, et al. Body mass, polymorphisms in obesity-related genes, and the risk of developing breast cancer among women with benign breast disease. Cancer Detect Prev. 2007;31(2):95-101. doi: 10.1016/j.cdp.2007.02.004. [PubMed: 17428620].

18. Okobia MN, Bunker CH, Garte SJ, Zmuda JM, Ezeome ER, Anyanwu SN, et al. Leptin receptor Gln223Arg polymorphism and breast cancer risk in Nigerian women: A case control study. BMC Cancer. 2008;8:338. doi: 10.1186/1471-2407-8-338. [PubMed: 19017403]. [PubMed Central: PMC2613914]

19. Woo HY, Park H, Ki CS, Park YL, Bae WG. Relationships among serum leptin, leptin receptor gene polymorphisms, and breast cancer in Korea. Cancer Lett. 2006;237(1):137-42. doi: 10.1016/j.canlet.2005.05.041. [PubMed: 16011872].

20. Nyante SJ, Gammon MD, Kaufman JS, Bensen JT, Lin DY, BarnholtzSloan JS, et al. Common genetic variation in adiponectin, leptin, and leptin receptor and association with breast cancer subtypes. Breast Cancer Res Treat. 2011;129(2):593-606. doi: 10.1007/s10549-011-1517-z. [PubMed: 21516303]. [PubMed Central: PMC3355661].

21. El-Hussiny MA, Atwa MA, Rashad WE, Shaheen DA, Elkady NM. Leptin receptor Q223R polymorphism in Egyptian female patients with breast cancer. Contemp Oncol (Pozn). 2017;21(1):42-7. doi: 10.5114/wo.2017.66655. [PubMed: 28435397]. [PubMed Central: PMC5385477].

22. He J, Xi B, Ruiter R, Shi TY, Zhu ML, Wang MY, et al. Association of LEP G2548A and LEPR Q223R polymorphisms with cancer susceptibility: Evidence from a meta-analysis. PLoS One. 2013;8(10). e75135. doi: 10.1371/journal.pone.0075135. [PubMed: 24146750]. [PubMed Central: PMC3798550]. 